\title{
"Essa tal de sociedade não existe.
0 privado, o popular e o perito no talk show Casos de Família
}

\section{João Freire Filho, Mayka Castellano e Isabela Fraga}

\section{Resumo}

A partir de um estudo de caso do talk show vespertino Casos de Família (SBT), este artigo pretende contribuir para a formulação de novos parâmetros de análise dos prazeres, dos significados culturais e das implicações sociopolíticas da atual voga de exposição da vida privada de "pessoas comuns". Como Casos de Família se aproxima ou se distancia das matrizes do melodrama e do realismo grotesco, tradicionalmente acionadas pelos programas populares no Brasil? Que valores são privilegiados pelo talk show? Como eles se conectam com a construção de formas de subjetividade fundamentais para o exercício do poder na sociedade contemporânea? Estas são as questões essenciais inter-relacionadas que planejamos responder no âmbito de uma pesquisa mais abrangente acerca das renovadas estratégias de incorporação e interpelação do popular na TV.

Palavras-chave

Casos de Família. Talk show. Matrizes populares. Vida privada. Poder.

\section{João Freire Filho | jofreirefilho@hotmail.com}

Doutor em Literatura. Professor Adjunto da Universidade Federal do Rio de Janeiro - UFRJ.

\section{Mayka Castellano | maykacastellano@gmail.com}

Mestranda do curso de Comunicação e Cultura da Escola de Comunicação da Universidade Federal do Rio de Janeiro - UFRJ.

\section{Isabela Fraga | belamof@hotmail.com}

Graduanda do curso de jornalismo da Escola de Comunicação da Universidade Federal do Rio de Janeiro - UFRJ. Bolsista PBIC do CNPq.

Uma coisa que me chama a atenção é a dificuldade de conversar. Às vezes, é mais fácil vir aqui, na frente de pessoas que você nunca viu, conversar de assuntos tão íntimos, tão delicados... Há dificuldade em conversar sobre isso na casa de vocês, que seria um lugar muito mais apropriado,

uma olhando para outra - só as duas, né? -, o que ficou conversado ali ficaria ali.

Regina Volpato, anfitriã de Casos de Família, no encerramento do programa exibido em 29 de outubro de 2007

\section{Introdução}

Os novos gêneros e formatos televisivos têm sido rechaçados por críticos mundo afora como o ápice da sordidez midiática ("telebasura", "trash TV", "garbage TV", "télé poubelle", "televisione spazzatura”...). A má reputação dos reality e talk shows se deve, sobretudo, à audácia com que convertem em espetáculo mercadológico assuntos, emoções, sentimentos e relações interpessoais historicamente circunscritos ao ambiente doméstico, ao confessionário religioso ou ao consultório terapêutico. As invectivas contra a desfaçatez dos participantes dos shows da intimidade são acompanhadas, amiúde, por lamúrias 
jornalísticas e conjecturas acadêmicas acerca da curiosidade mórbida do público. Tanto 0 ímpeto moralizante quanto o uso indiscriminado da noção de voyeurismo atravancam 0 entendimento das condições de emergência e da popularidade de uma safra variada de atrações televisivas cujo denominador comum é a promessa de fornecer a visualização (ao mesmo tempo, reveladora e entretida) dos compromissos éticos, do estado psíquico, das condições emocionais e das inclinações afetivas de um casting de anônimos, focalizados em situações cotidianas ou inusitadas.

0 objetivo deste artigo é, justamente, contribuir para a formulação de novos parâmetros de investigação dos prazeres, dos significados culturais e das implicações sociopolíticas da atual voga de exposição midiática das intimidades de "pessoas comuns" (ou seja, não pertencentes às elites dirigente, econômica e intelectual, nem ao panteão das personalidades do esporte, da moda e do entretenimento). Nossas reflexões se fundamentam, prioritariamente, na análise de Casos de Família (SBT), talk show vespertino que traz à cena conflitos afetivos e domésticos da população de baixa renda paulistana. ${ }^{1}$ Como Casos de Família - em sua organização temática, narrativa e estética - se aproxima ou distancia das matrizes do melodrama e do realismo grotesco, tradicionalmente acionadas pelos programas populares no Brasil? Que valores são privilegiados pelo talk show? Como eles se conectam com a construção de formas de subjetividade fundamentais para o exercício do poder contemporâneo? Estas são as questões essenciais inter-relacionadas que planejamos responder no âmbito de uma pesquisa mais abrangente acerca das renovadas estratégias de incorporação e interpelação do popular na TV. 0 que apresentamos a seguir consiste numa síntese (bastante seletiva, é claro) de observações e conclusões delineadas em cada etapa de nossa abordagem exploratória de Casos de Família.

\section{Um programa família}

Ao que tudo indica, o influente quadro de referência focado na "comunicação do grotesco" (Mira, 1995; Sodré, [1972] 1992; Sodré \& Paiva, 2002) não é capaz de elucidar,

0 estudo se apoiou no monitoramento regular de Casos de Família durante os meses de abril, maio e junho de 2007 e agosto, setembro e outubro de 2008; 0 cerne da análise textual, porém, foram os vinte programas exibidos de 08 de setembro a 03 de outubro de 2008. A amostra selecionada foi transcrita de acordo com o convencional sistema de duas colunas (a primeira contendo a descrição de aspectos visuais, destacando quem ou que estava sendo mostrado, sob que ângulo de câmera, e qual a ação realizada; a segunda fornecendo a descrição de elementos verbais, incluindo o tom e a ênfase). A sondagem inicial do corpus permitiu a categorização dos temas veiculados e a identificação de pontos de confluência e discrepância genérica com os talks shows produzidos no Brasil e no exterior. A segunda etapa investigativa se concentrou no exame mais pormenorizado do papel e do status conferidos à anfitriã, ao perito e aos convidados do programa. Sem qualquer pretensão de efetuar uma "abordagem multiperspectivística" nos moldes propostos por Kellner (2001), incorporamos ao nosso acervo analítico dados relativos à produção do talk show (provenientes de informes oficiais elaborados pelo SBT, de entrevistas publicadas na imprensa e, sobretudo, da pesquisa etnográfica empreendida por Gomes, 2007) e à sua recepção (textos secundários ou intertextos, para usar a nomenclatura de Fiske (1989), veiculados por fãs e detratores em sites, em blogs e no Orkut). 
inteiramente, as novas formas de admissão e (des)articulação do popular na TV. Hoje em dia, deixou de ser obrigatório exibir defeitos físicos ou morais impactantes, revelar notável talento (ou incompetência) vocal, realizar façanhas circenses ou prantear infortúnios econômicos desesperadores para figurar diante das câmeras. 0 traço distintivo da atual incorporação do povo na TV é a magnitude com que ela abarca os anônimos sem qualidades admiráveis, compleição corporal aberrante ou mazelas tremendas. Sobem à ribalta televisiva indivíduos cujo único predicado mais perceptível é a disposição para descortinar suas intimidades, com certa fluidez e expressividade, fora do ambiente privado ou clínico - em "rede nacional", conforme costumava repetir o vencedor de uma das edições do Big Brother Brasil.

Poucos programas em exibição na TV brasileira evidenciam essa tendência de maneira tão cristalina quanto Casos de Família. Nesse talk show popular de considerável desempenho comercial2 , os "homens do povo" (ou, mais assiduamente, as "mulheres do povo") relatam problemas prosaicos da vida cotidiana. 0 esperado, o corriqueiro, o comum têm primazia sobre o singular, o raro, o anômalo, o estranho. A encenação do grotesco e o espetáculo da miséria - sempre sujeitos a imprevistos, desordens, matérias furiosas da imprensa, ameaças de censura (sob a acusação, durante o regime militar, de pôr em risco a Segurança Nacional e, mais recentemente, de desrespeito aos Direitos Humanos) e fuga precavida de anunciantes cedem espaço à exposição mais bem-comportada de vivências íntimas e dissabores domésticos. Nada de sensacionalismo, morbidez ou carnaval fora de época. ${ }^{3}$ No lugar da excepcionalidade do mundo cãa, privilegia-se a banalidade do mundano, avaliado como aquilo que caracteriza a rotina da vida prática - experiências, conhecimentos, rituais e identidades

No ar desde 0 dia 18 de maio de 2004, o talk show tem assegurado à emissora de Silvio Santos, atualmente, a vice-liderança de audiência no horário das $16 \mathrm{~h}$ às 17h, com média de 9 pontos e picos de 12 pontos (de acordo com dados do lbope/Telereport - Praça São Paulo), perdendo para a Sessão da Tarde da TV Globo, mas mantendo-se à frente do Programa da Tarde da TV Record. Em 11 de junho de 2008, Casos de Família chegou a liderar a audiência por cinco minutos, com a discussão do tema "Minha mulher me bate". A exibição do programa "Meu ex não me deixa ter outro relacionamento", em 26 de junho de 2006, obteve média de 12 pontos e pico de 15 pontos, os índices mais expressivos já conquistados pela atração.

Em sua home page, Casos de Família ("um novo conceito na discussão de temas do cotidiano") é anunciado, a propósito, como "um talk show diferente que retrata a vida de cidadãos comuns com realidade e sensibilidade. Diariamente, o programa traz temas do cotidiano que vão ressaltar as emoções dos participantes presentes no palco, da platéia convidada e dos telespectadores que estão em casa, resgatando valores sem apelar para provocações ou escândalos. Os protagonistas de cada uma das histórias relatadas, (sic) são pessoas anônimas que revelam seus sentimentos com sinceridade e verdade. Além dos convidados, a platéia também participa ativamente do programa com opiniões e perguntas sobre as histórias relatadas. A intenção é orientar e até mesmo solucionar os casos apresentados contando com a participação de um profissional especializado em comportamento. A experiente jornalista Regina Volpato conduz o bate-papo com uma postura sóbria e imparcial. Usando o bom senso, ela opina, interage com a platéia e conversa sobre os casos com o especialista convidado pelo programa" (Disponível em: <http://www.sbt. com.br/casos_familia/programa/>. Acesso em: ago. 2008) 
firmemente incrustados no dia-a-dia da "gente comum". ${ }^{4}$

As pessoas anônimas são acolhidas no palco de Casos de Família na essência de sua condição ordinária. É oportuno lembrar, aqui, que ordinário (do latim ordinarius) significava, em sua acepção original, "disposto em ordem", "de acordo com a organização normal ou 0 padrão regular", "em conformidade com a regra e a autoridade". 0 vocábulo integra, portanto, uma populosa família de termos que denotam freqüência e estabilidade: ordeiro; ordenado; ordenança; ordinária (gasto periódico; pensão alimentícia); coordenado; subordinado... 0 programa conduzido (com inquebrantável serenidade) pela jornalista Regina Volpato se afigura, nesse sentido, como a província do lugarcomum, do habitual, do medíocre, do convencional que contrasta com o choque do excêntrico, do extravagante, do extraordinário promovido, periodicamente, por shows de calouros, programas de auditório e telejornais policiais.

\section{Embora o site de Casos de Família encoraje 0} telespectador a relatar seu drama privado, trinta "pesquisadores" do programa (estagiários de rádio e TV) saem às ruas da periferia de São Paulo atrás de personagens exemplares, vinculados aos temas definidos em reunião de pauta pelos produtores (com base em sua experiência pessoal ou em reportagens de jornais e publicações femininas).

A equipe do programa entrevista previamente os candidatos a participantes. A fim de evitar qualquer tipo de tramóia, são consultados documentos, fotos e cartas que atestem alegadas relações de parentesco ou amizade. Descartada a hipótese de embuste, selecionam-se os postulantes com maior desembaraço e uma história mais atrativa para contar. Os escolhidos assinam um termo de compromisso (afiançando a veracidade dos fatos a serem relatos) e recebem um cachê de $\mathrm{R} \$ 80,00$ (Gomes, 2007, p. 65-69).

Na seleção comercialmente criteriosa das histórias da vida cotidiana, são favorecidas experiências pessoais capazes de despertar 0 interesse e a identificação cúmplice ou condolente do público, graças ao seu caráter individual e autêntico e, ao mesmo tempo, modelar e representativo. "Quem não convive com alguém que fala demais? Quem já não lamentou a ingratidão de um parente? Quem já não suspeitou que uma amiga lhe traíra a confiança?" Essa parece ser a premissa que norteia a confecção de Casos de Família, assumidamente calcado no talk show peruano Mónica. ${ }^{5} 0$ SBT

Não por acaso, mundane é um dos qualificativos adotados, em países de língua inglesa, por fãs de ficção científica e integrantes da subcultura gótica para discriminar pessoas destituídas de imaginação, vinculadas a estilos de vida e gostos musicais e artísticos previsíveis, enfadonhos.

Exibido no Peru entre 1999 e 2005, o talk show Mónica passou a ser retransmitido, desde 2000, para doze países latinoamericanos e para os Estados Unidos, através da Telemundo e da Telefutura. A apresentadora Mónica Zevallos - também conhecida como "La suavecita" (graças à doçura com que se comporta em cena) - iniciou sua carreira de jornalista como âncora do telejornal Esta Manãna. Atualmente com 40 anos de idade, Mónica (branca, olhos azuis, cabelos louros platinados) desfruta de grande prestígio entre o público peruano, tendo lançado uma revista feminina com o seu nome. 
adquiriu os direitos do formato do programa em 2004, conservando elementos estruturantes centrais (como o horário vespertino, o décor, a disposição dos convidados no palco e as considerações finais de um psicólogo); alcunhada pela imprensa, nos anos 1980, de "Sistema Brega de Televisão", a emissora tomou a precaução, todavia, de promover modificações relevantes no perfil da matriz castelhana, descartando os atributos morais e estéticos mais escandalosos:

No visual da apresentadora, era uma maquiagem muito carregada, 0 figurino era 0 que a gente vê muito em novela mexicana, aquela coisa muito forte. (...) No conteúdo eles seguiam aquela forma de bate-boca no programa, agressão jamais, mas assim de discussão, da platéia levantar e fazer perguntas agressivas, e isso a gente achou que não dava, que não era bacana, que já tinha sido feito em outros programas, neste mesmo estilo. (...) A gente fez só essas alterações, para tornar o programa mais leve e que qualquer pessoa pudesse assistir, sem achar que aquilo era ofensivo, grotesco (Melissa Ribeiro, assistente de direção e produtora de Casos de Família, apud Gomes, 2007, p. 45). ${ }^{6}$

Com seu estilo mais light de incorporação e interpelação do popular, Casos de Família vem conseguindo sobreviver às consecutivas mudanças na grade de programação do SBT, empreendidas principalmente na faixa vespertina. Atualmente, o programa vai ao ar de segunda à sexta-feira, das $16 \mathrm{~h}$ às $17 \mathrm{~h}$. No total, são quatro blocos com cerca de nove minutos, intercalados por anúncios e merchandising de produtos populares ligados à beleza feminina, aos afazeres domésticos e à saúde pessoal e financeira, como o creme para varizes Varicell, a tintura de cabelos Márcia, o sabão em pó Blanc 02, a Raspadinha da Loterj, a Tele-Sena e os serviços da BV Financeira.

A cada dia, Casos de Família enfoca um tema diferente, emoldurado por rubricas incisivas que predeterminam 0 ângulo de abordagem das crises domésticas. Na semana de 15 a 19 de setembro de 2008, por exemplo, os tópicos abordados foram: "Eu não tenho culpa dos seus problemas fora de casa" (mulheres se queixam dos companheiros que sempre chegam em casa nervosos e mal-humorados); "Se você não me sustentar, eu vou embora de casa" (filhos que acreditam ser obrigação dos pais sustentá-los, mesmo depois de mais velhos); "Deixei de ser a preferida, desde que você chegou" (filhos/ sobrinhos/amigos reclamam que foram preteridos por novos moradores da casa); "Meus filhos não precisam de você" (mães dizem que os filhos não necessitam do amor de avós/pais/padrastos relapsos); "Você reclama de barriga cheia" (mães/filhas protestam que suas filhas/mães nunca estão satisfeitas com a ajuda financeira que recebem).

Na compilação de imagens do programa Mónica ("el verdadero show de la conversación”) disponível na Internet (www. alomiproducciones.com), ficam patentes as diferenças em relação a Casos de Família. No talk show peruano, os convidados se exaltam, trocam insultos e empurrões, refutam a anfitriã (que nem sempre faz jus ao apelido de "suavezinha"...), a câmera ultrapassa o plano médio, efetuando close-ups nos momentos mais intensos das discussões. Para desanuviar 0 ambiente, há momentos de comicidade rasteira e espetáculos de dança (às vezes, com a participação de Mónica). 
A dinâmica do programa contempla, em regra, uma mesma estrutura sequiêncial de introdução, prospecção e interpretação das querelas familiares, mediante a apresentação dos relatos autobiográficos dos convidados, da abordagem interrogativa da anfitriã e do discurso analítico e prescritivo do psicólogo.

Antes mesmo da vinheta de abertura, Regina Volpato aparece em pé no cenário do programa e faz uma breve apresentação do tema do dia, dirigindo-se, pausadamente, aos telespectadores:

Você tem um parente passando muita dificuldade e, para ajudá-lo, resolveu trazê-lo para morar na sua casa. 0 problema é que, agora, você precisa que ele saia. Mas isso está longe de acontecer. Ele diz que não tem para aonde ir e que você está sendo muito egoísta. Você não agüenta mais essa situação e acredita que já está na hora de ele se mexer e procurar um outro lugar para morar. "Até quando você vai ficar em minha casa?" é o nosso tema de hoje.

Embora se baseie em experiências previamente relatadas pelos participantes à equipe de produção, $o$ texto inicial prioriza sempre a forma de tratamento de segunda pessoa ("Você tem", "Você acha", "Você precisa", "Você não agüenta"...) como recurso retórico para fortalecer, de imediato, a adesão do público de casa e garantir sua inserção na ambiência do programa.

Depois da introdução feita pela apresentadora, é exibida a vinheta de abertura, embalada por uma trilha sonora instrumental bastante jovial e aderente à memória. Numa edição videoclipada, sucedem-se imagens radiantes de Regina preparando café-da-manhã para a filha, passeando com o cachorro, exercitando-se numa academia, comprando alimentos na feira, chegando de automóvel ao estúdio do SBT e, por fim, parada no cenário do programa, risonha, ao lado de uma câmera. Um modo bastante direto de apresentá-la como "uma mulher igual a você", "gente como a gente", que trabalha fora, mas que também precisa zelar pela casa, pelos filhos e até pelos animais de estimação - sem perder o bom humor. Ninguém ousaria negar a fama de Regina Volpato (sua imagem está estampada nas capas das revistas de TV, como constatamos em determinado momento da vinheta); o sucesso, todavia, não lhe mantém olimpicamente afastada das múltiplas obrigações e preocupações enfrentadas diariamente pelos anônimos. "É tudo gente normal, aqui, não tem estrela, não tem gente com mais problema ou menos problema, é tudo gente normal conversando com respeito, só isso!", garante a anfitriã (apud GOMES, 2007: 49), embora seja difícil acreditar que, na prática, a maioria da platéia e dos convidados disponha de tempo para fazer ginástica ou de recursos financeiros para comprar um carro.

Logo após a agregadora vinheta de abertura, Regina Volpato já aparece acomodada numa cadeira centralizada pouco à frente da platéia do programa. Seu ponto de vista - pelo menos no que tange à localização espacial - é semelhante, portanto, ao das 80 pessoas que compõem aproximadamente a audiência no estúdio (99\% delas, do sexo feminino). Com ar de contida 
satisfação, Regina introduz a primeira participante, lendo um sucinto depoimento prévio; a convidada entra no palco sob aplausos, e ocupa uma cadeira defronte da apresentadora e da platéia.

A cada bloco, é focalizado um imbróglio familiar, a partir de entrevistas individuais com uma dupla de participantes. Regina ouve (com atenção e ternura altiva) os desabafos e as reclamações do primeiro convidado, solicitandolhe esclarecimentos sobre detalhes da desavença familiar e propondo-lhe reflexões acerca de aspectos problemáticos de sua vida doméstica e emocional; demonstrando empatia ("Que situação complicada, não?"), formula, de vez em quando, comentários mais gerais a propósito dos enigmas da convivência humana. Logo em seguida, a outra parte envolvida na história é chamada para defender-se, oferecendo sua versão dos fatos. Apupos moderados do público pontuam, não raro, as declarações mais polêmicas ("Nunca fui mesmo de dar carinho aos meus filhos"; "Chega de ficar em casa cuidando dos netos, agora eu quero ir para a balada"; "Carregou a filha, tem de levar a mãe junto também"...). Às vezes, a pós-produção do programa insere, durante os depoimentos, rápidas tomadas de integrantes da platéia com expressão facial de discordância ou divertimento. Mesmo durante a troca de acusações, os convidados, em geral, não se encaram, preferindo fixar o olhar na direção de Regina. Ninguém jamais se levanta da cadeira.

Concluída a réplica do segundo participante, Regina conduz o microfone até a platéia, para uma breve sessão de perguntas ou avaliações de índole moralizante ou edificante... "Gente, em vez de ficarem tanto tempo no banheiro, por que vocês não vão ler um bom livro? Vamos alimentar o cérebro! Um... Eça de Queiroz, um... Machado de Assis." ("Victor Hugo também é muito bom", complementou a anfitriã) ("Você passa muito tempo no banheiro", 08/09/08). No bloco seguinte, outro caso é apresentado, obedecendo à mesma fórmula anterior. Ao fim da acareação com as duas partes em litígio, perguntas podem ser direcionadas para o caso em pauta ou para o precedente, já que a primeira dupla de entrevistados permanece no palco.

No último segmento do programa, todos os convidados (seis, em regra) estão dispostos ombro a ombro na sala de estar simulada pelo cenário. Sentado ao lado de Regina, o psicólogo do programa tece observações a propósito da história de cada unidade familiar, orientando e interpelando diretamente os integrantes. ${ }^{7}$ Depois

Atualmente, dois psicólogos se revezam no programa: Ildo Rosa da Fonseca, negro, na faixa dos 40 anos, invariavelmente trajado de terno e gravata, e Anahy D'amico, branca, 50 anos presumíveis, igualmente bem-arrumada, porém com um estilo mais descontraído, em que se destacam as peças coloridas e um moderno óculos de grau. São extremamente escassas as informações a respeito de ambos os profissionais no site de busca Google. Todas as referências à Anahy são oriundas de comentários do blog de Regina Volpato; no caso de Ildo, encontram-se, além disso, dois registros de palestras ministradas por ele: "Reencarnação e livre arbítrio (sic)", no Instituto Espírita de Educação, e "Relação familiar e relação conjugal: um encontro possível", "Sede perfeitos" e "As três revelações", no Centro Espírita Ismael. 
da análise e dos aconselhamentos do expert, a apresentadora expressa suas considerações finais, enquanto começam a ser exibidos os créditos do programa ao pé da tela. ${ }^{8}$ Para encerrar, a anfitriã agradece a participação dos convidados e a companhia do público de casa, desejando que todos fiquem com Deus.

\section{Um gênero feminino}

Os talk shows populares constituem uma hibridação (menos ou mais turbulenta) da estrutura dos debates jornalísticos, do público participativo dos programas de auditório e da temática privada dos reality shows. Em Casos de Família, podemos encontrar 10 características comumente discerníveis no terreno cambiante desse amálgama genérico: 1) codificação da intimidade como forma e substância do programa; 2) veiculação de discursos (confidenciais, testemunhais e confrontadores) de pessoas anônimas; 2) exposição de conflitos de interesses, perspectivas e valores em torno de um aspecto predeterminado da vida íntima; 3) preponderância da orquestração de narrativas personalizadas e emocionais em detrimento da argumentação e da deliberação racional;

4) cenário que simula uma sala de estar de classe média; 5) participação do público do estúdio, por meio de perguntas e avaliações que traduzem, idealmente, opiniões e inquietações do público de casa; 6) presença de um "especialista em comportamento", com reputada competência para guiar os convidados na superação de tormentos cotidianos; 7) atuação central de uma anfitriã de classe média, com autoridade para controlar o tom e o fluxo da conversação, agindo como mediadora das intervenções dos convidados, da platéia e do expert; 8) baixo custo de produção; 9) exibição fora do horário noturno; 10) platéia e audiência majoritariamente femininas. ${ }^{9}$ Fiel a esses parâmetros basilares, o programa traz como marco distintivo subgenérico a intencionalidade comunicativa específica de contribuir para resolver ou remediar contendas familiares, oferecendo soluções afinadas com a sensibilidade terapêutica e o ethôs da autoajuda que se espraiam por grande parte da produção midiática contemporânea (Dubrofsky, 2007; Freire Filho, 2007a; Peck, 1995; Mehl, 1996, 2002, 2003, 2007; White, 1992, 2002) -

Segundo Regina, o propósito desta derradeira intervenção é “(...) fazer um apanhado geral, dar uma esclarecida nos pontos, fechar algumas amarras. Às vezes, alguém que eu sinto muito fragilizada, ou que não gostou do que ouviu. Então, é preciso dar um amparo, entendeu? Não é justo trazer alguém aqui para falar, conversar e, acaba o programa, vai embora e fim, sem uma conclusão qualquer, se não para a situação, ao menos para o que foi dito. Às vezes são pessoas, assim, humildes na fala, mas de uma nobreza de raciocínio, uma nobreza de caráter..., isto precisa ser dito! Olha, gostei do que a senhora disse, foi muito clara e franca e tal. (...) Minha função é essa, é conduzir e no final, como se fosse o final de um capítulo de novela, amanhã tem mais e só" (apud Gomes, 2007: 79).

A respeito da história e da morfologia dos talk shows no contexto norte-americano e europeu, consultar Charaudeau \& Ghiglione (1997); Imbert (2003: 123-142); Cortés Lahera (1999, p. 199-205); Livingstone \& Lunt (1994); Shattuc (1997, 2005); Zalduendo (2000). 
notadamente, pelos artefatos com pronunciado apelo feminino. ${ }^{10}$

Casos de Família alça as mulheres ao centro do dispositivo televisivo, seja como público, seja como apresentadora, ou, ainda, como convidadas (na condição de esposa, mãe, amiga, dona de casa ou chefe de família; a situação profissional, quando referida, é renegada a um plano bastante secundário). Em geral, são as mulheres, também, que ocupam o posto de reclamante, cabendo ao homem 0 lugar de interpelado.

A comparação efetuada por Regina Volpato, no final da seção anterior, entre as edições de Casos de Família e os capítulos de uma telenovela não é fortuita. Tanto os talk shows quanto as ficções seriadas populares têm sido cultural e comercialmente associadas a uma sensibilidade e uma audiência femininas, com base na convenção genérica de que tanto a escancarada exibição de emoções quanto o interesse nas revelações confidenciais alheias são apanágios das mulheres. Algumas das questões mais constantemente enfocadas pelo programa do SBT - desilusões amorosas ("Só me envolvo com homens problemáticos"; "Meu marido me dá menos do que eu mereço"; "Ele vive me comparando com a ex"; "Meu marido se comporta como um general"; "Suas mentiras não me enganam mais"), tensões geracionais ("Meu filho é muito agressivo"; "Meu filho não me respeita"; "Minha mãe precisa ser mais moderna"; "Minha mãe atrapalha meu casamento") e os obstáculos para a emancipação da mulher no âmbito da organização familiar patriarcal ("Meu marido não aceita que eu trabalhe"; "Ela largou o emprego para ser dona de casa"; "Quero me separar, mas ninguém me apóia") - evidenciam a filiação à matriz melodramática, com sua ênfase na representação das paixões, tormentas, decepções, repressões e renúncias femininas.

Às vezes, os conflitos domésticos são abordados, dentro de Casos de Família, como resultantes de duas visões de mundo ou opções de vida divergentes, mas moralmente respeitáveis. Em muitas oportunidades, porém, o desenrolar das discussões evoca a polarização moral melodramática, alicerçada na distribuição inequívoca e transparente de vício e virtude (com o "marido infiel", a "filha mimada" e a "amiga traiçoeira" ocupando, no caso, o papel de vilão).

Os melodramas televisivos clássicos (como as novelas mexicanas reproduzidas assiduamente pelo SBT, até pouco tempo atrás) e Casos de Família comportam diferenças notáveis, entretanto, em suas estratégias para tornar interessantes a vida privada e os infortúnios domésticos. 0 talk show vespertino evita, de maneira deliberada, a "dramaturgia da

10 Não por acaso, as orientações dos experts em aparência e no cuidado da alma são endereçadas preferencialmente às mulheres, cuja identidade tem sido tipicamente construída e analisada em termos de falta, desapontamento, instabilidade e insatisfação consigo mesma. 
hipérbole, do excesso e da excitação", a "estética expressionista ou histérica", a "mise-en-scène conspicuamente saturada", "os movimentos exagerados de câmera", "o modo vulgar de atuar", "a pretensão de intensidade", "0 afã em produzir efeitos portentosos", "a tendência ao esbanjamento" que distinguem estilisticamente o melodrama, segundo seus estudiosos mais proeminentes (Brooks, 1984; Landy, 1991; MartínBarbero, 2002; Singer, 2001).

0 cenário de Casos de Família (com ênfase nos tons pastéis) é bastante despojado, discreto, clean, se comparado aos dos folhetins mexicanos (ou aos das atrações comandadas por Hebe Camargo, Ione Borges e Claudete Troiano, entre outras vedetes da "programação feminina" da televisão brasileira). 0 trabalho de edição e sonoplastia também é marcado por relativa sobriedade: não se oferta ao telespectador os habituais close-ups em busca de lágrimas furtivas ou outras expressões faciais e gestuais de comoção interior; tampouco são utilizadas músicas incidentais destinadas a sublinhar 0 caráter emotivo dos depoimentos; além disso, 0 gerador de caracteres que sintetiza, de tempos em tempos, o conteúdo das declarações dos convidados descarta manchetes garrafais, adjetivações e exclamações bombásticas.

Conforme detalharemos a seguir, a postura da anfitriã é crucial para que a conversação íntima ou confidencial de Casos de Família pareça caminhar no sentido da prometida resolução de conflitos, mantendo o seu apelo de entretenimento.

\section{Uma anfitriã de classe}

Formada em relações públicas pela USP e em jornalismo pela Universidade Anhembi Morumbi, com experiência como repórter da Fundação Roberto Marinho e âncora da Band News, a paulista Regina Volpato, 40 anos, não se encaixa no estereótipo dos condutores de programas que mostram "0 povo na TV". Seu estilo difere radicalmente do visual extravagante ("perua") e da atitude aguerrida ("barraqueira") de Márcia Goldschmidt ("Mexeu com você, mexeu comigo"), sua concorrente mais direta. Tampouco identificamos na anfitriã de Casos de Família vestígios da performance intensa e histriônica (oscilando entre o cômico e o colérico) de animadores populares como Ratinho (ex-palhaço de circo, engraxate, limpador de defuntos, feirante e vendedor de "churrasquinho de gato"), cuja comunicação carismática se fundamenta na alardeada recusa de todo artificialismo, de toda hipocrisia, de toda forma de distanciamento da alma, do linguajar, dos costumes e dos interesses do povo. A persona televisiva de Regina é extremamente $c o o l$, seu vestuário prima pela elegância, sua linguagem nunca é vulgar, sua voz jamais abandona 0 tom baixo e cortês. 0 charme da apresentadora parece residir, sobretudo, em sua capacidade de transmitir - além de interesse e compreensão - tranqüilidade e segurança para a platéia, 
os convidados e o público, poupando-os de situações embaraçosas.

Em depoimento concedido ao site da rádio Jovem Pan, Regina afirmou que continua realizando, no talk show do SBT, um "trabalho de jornalista" - "Trabalhar no Casos de Família ou em qualquer outro programa de entrevistas seria a mesma coisa." A ausência de "barraco" (“confusão, rolo, quizumba", consoante 0 Aurélio) ao longo do programa seria decorrência de sua preocupação constante com a "isenção", a "objetividade" - "Acho que o jeito que eu faço o programa é o meu jeito". ${ }^{11}$

Comentários de telespectadores de Casos de Família veiculados em sites e blogs parecem corroborar o apelo do estilo low profile do programa. ${ }^{12}$ Quando o clima do debate se torna mais candente, os próprios entrevistados costumam lançar olhares apreensivos para Regina, cientes de que estão transgredindo uma regra estabelecida pela produção. ${ }^{13} \mathrm{Se}$ algum participante insiste em "tomar conta do programa", atravancando o depoimento de outro convidado, a anfitriã intervém com a afabilidade e a firmeza que caracterizam a relação entre adultos e crianças. Durante a discussão do tema "Se você não me sustentar, eu vou embora de casa" (16/09/2008), Márcia, 24 anos, teimava em interromper os pais, sentados ao seu lado - "Márcia, nós devemos deixar os mais velhos falarem primeiro", censurou Regina, com inflexão professoral. A platéia aplaudiu entusiasmada.

A beleza discreta de Regina (ela trabalhou como modelo da agência Ford) e sua postura de confidente sábia (sem ser presunçosa), gentil e confiável vêm aglutinando fãs também no ciberespaço. Existem 49 comunidades no Orkut consagradas especialmente à apresentadora desde a clássica "Eu amo Regina Volpato" (com cerca de 2.700 membros) até variantes mais específicas do tipo "Regina Volpato é linda", "Regina Volpato é exemplo", "Eu tenho tesão na Regina Volpato"... Mesmo nas 50 comunidades

Disponível em: <http://jovempan.uol.com.br/jp/media/online/index.php?view=14681\&categoria=57>. Acesso em: ago. 2008.

"E o que é mais importante: [Regina Volpato] sabe como lidar e respeita os convidados sem deixar que os mesmos tomem conta do programa. E o que mais me admira é a forma como ela entrevista a todos sendo imparcial e não deixando que eles atrapalhem os outros"; "Eu gosto porque ela não põe fogo no programa, não incentiva o barraco, ela resolve os problemas sem gritar, parece uma fada"; "Nunca fui fã de programas populares, mas tive que abrir uma exceção para esse. Se vocês analisaram bem, repararam que só POBRES vão no programa (sem querer explicitar um preconceito social, pelo amor de deus, mas são pessoas muito humildes, sem muito pudor). Até, pq, uma pessoa em sã consciência não se sujeitaria a isso. Não gostaria de me expor dessa forma. Mas essa apresentadora é tão fantástica, que consegue fazer um programa aparentemente tosco transformar-se em algo até inteligente. Pela sua simpatia, pela sua forma de conduzir o programa e discussões, mas principalmente, pelo seu talento. Profissionais como ela estão extintos nesse mundo jornalístico competitivo. Ela não é qualquer uma. Ela merece o posto em que se encontra, e até muito mais que isso. Posso ser sincera?? Não sou de babar ovo por ninguém, MAS EU AMO ESSA MULHER! rs...".

Antes de ser iniciada a gravação do programa, um integrante da produção alerta a platéia para o tipo de pergunta que deve ser evitado, acrescentando que ofensas não serão permitidas. Alguns minutos depois, Regina repete a advertência: nada de palavrões, questionamentos maliciosos, observações pejorativas e gracejos a respeito das pessoas em cena (GOMES, 2007, p. 60). 
dedicadas, de forma mais abrangente, ao programa Casos de Família, predominam declarações carinhosas, quando não apaixonadas, dirigidas à anfitriã. Na comunidade "Regina Volpato me entenderia", chama a atenção 0 tópico "A Márcia se acha, A REGINA... É", no qual se exalta a jornalista como "educada", "fina" e "compreensiva" (adjetivo reprisado em quase todos os comentários), enquanto Márcia Goldschmidt é rotulada de "vadia", "que põe lenha na fogueira", "amante da baixaria". Há somente três comunidades de repúdio à comunicadora do SBT: "Eu odeio Regina Volpato", "Regina Volpato é fofoqueira!!!" e "Regina Volpato é um Robô". Conforme prenuncia o seu nome de batismo, 0 alvo desta última comunidade é o comportamento alegadamente mecanizado da apresentadora: "Se você também acha que Regina Volpato é um robô programado para dizer sempre as mesmas coisas e repetir as mesmas frases sempre da mesma forma, essa é a SUA comunidade". A suposta frieza e falta de espontaneidade da anfitriã também são rejeitadas na comunidade "Regina Volpato é a mãe da Sandy", alusão à jovem cantora de imagem pública (tediosamente) pacata e virtuosa.

Em determinadas ocasiões, a "postura sóbria e imparcial" da apresentadora causa, de fato, certa estranheza para quem acompanha os programas populares na TV. Durante a apresentação do tema "Não há mais intimidade em nosso casamento" (10/09/2008), um participante revelou que as coisas mudaram muito em seu relacionamento conjugal depois que sua casa foi inteiramente consumida por um incêndio e, para piorar, 0 filho de dois meses faleceu, logo em seguida, devido a problemas cardíacos. Regina manteve o semblante inalterado, reagindo ao depoimento funesto com a mesma emoção de quem acabara de ouvir a previsão do tempo.

No período final de elaboração deste artigo, pudemos perceber, entretanto, uma ligeira modificação no comportamento mais distanciado (ou "objetivo") da apresentadora. Durante a apresentação dos tópicos "As suas manias me incomodam" (02/10/08) e "Eu preciso do seu perdão" (23/09/08), a anfitriã quebrou o protocolo, dirigiu-se ao palco, sentou-se do lado de convidados chorosos, oferecendo-lhes um lenço e tocando-lhes suavemente 0 ombro - compassiva, mas sem perder a classe.

\section{5 "Um retrato do Brasil"}

Então, quer conhecer o Brasil? Assiste Casos de Família: o sotaque, o português, a gíria, a maneira de se vestir, tudo! (...) Eu acho que mais que programa de entretenimento, a gente contribui para isso. Essa é a cara do Brasil, essas são as nossas necessidades. $O$ retrato de tudo que éfeito na política está aqui. Essas pessoas vivem a falta de tudo, aquilo que a gente sabe que falta, mas a gente não vivencia e eles vivenciam e isso influi na moral, nos costumes, na saúde. É impressionante! É impressionante como essas pessoas vivem à margem.

Regina Volpato, apud Gomes (2007, p. 36) 
Em que pese a estupefação de Regina Volpato ao deparar-se com a personificação da exclusão social ("Você vê em carne e osso 0 que vê no papel, em dados e estatísticas"), Casos de Família não se apresenta como o lócus de ativação de sentimentos viscerais ou impulsos primários de revolta diante do suplício das vítimas da concentração de renda e da inoperância do poder público no Brasil. 0 programa não pretende cumprir o papel de tribunal de pequenas causas, pronto-socorro ou justiceiro eletrônico. Não alardeia a intenção de remediar a negligência do Estado nas áreas de habitação e saneamento básico, saúde e segurança pública ou no combate ao desemprego. Trata-se, na verdade, de uma simulação ligeira de consultório emocional e de terapia de grupo, que evoca, nos instantes de maior distensão, as fofocas partilhadas num almoço entre amigas.

A apresentadora e o psicólogo (expert que veio ocupar o lugar dos advogados e médicos tão assíduos em $O$ Povo na TV, Ratinho Livre e adjacências) ouvem histórias de vida e oferecem análises, informações e receitas pontuais que ambicionam contribuir para a administração ou o desenlace de situações de conflito. Da disposição franca dos participantes para 0 desvelamento da intimidade - somada à reavaliação conjunta de idéias, sentimentos e formas de conduta individual - decorrerá, supõe-se, o aprimoramento da comunicação e da interação familiar. Estima-se, ainda, que 0 "público de casa" não apenas vai se emocionar como também poderá aprender com a abordagem das aflições alheias, alcançando a resolução de problemas equivalentes.

0 universo temático de Casos de Família pode parecer, à primeira vista, inviavelmente tacanho para uma atração diária. 0 programa opera, no entanto, com uma concepção de família que não corresponde à versão especializada moderna, restrita a um pequeno grupo de pessoas ligadas entre si pelo casamento e pela filiação e que reside, geralmente, sob o mesmo teto. Os sentimentos de abandono, incompreensão, traição, injustiça, frustração e raiva focalizados pelo programa germinam em uma comunidade afetiva e funcional um pouco mais ampla, abrangendo parentes em segundo grau, colegas e vizinhos. Casos de Família mostra, nesse sentido, não estar alheio às formas tradicionais de sociabilidade e às estratégias de sobrevivência dos estratos populares menos favorecidos - com suas redes de relações solidárias, seu sistema de ajuda mútua, suas trocas de favores, mas também suas cobranças implacáveis e suas intromissões indesejadas.

A violação do princípio da reciprocidade é causa freqüente das lamentações dos participantes do programa. Tensões brotam, ainda, da proximidade compulsória, da obrigatoriedade de partilhar espaços domésticos, áreas de serviço, quintais e utensílios. Especulações maldosas desencadeiam divergências entre casais e entre amigas. 
Ao mesmo tempo em que contempla esse rol de problemas, Casos de Família revela uma preocupação sistemática em impedir que aflorem as significativas conexões entre as queixas, os descontentamentos, as rivalidades declaradas e as condições concretas de vida dos entrevistados: baixos salários, habitações precárias, falta de cômodos... A formatação do programa não concebe o privado como o lugar onde o povo experimenta, cotidianamente, a privação econômica, mas como espaço de vivência de déficits comunicacionais e carências afetivas universais. "Quem é que não tem um conflito com o marido, com o filho, porque a gente trata basicamente disso, dos conflitos familiares, são temas de todo dia, são coisas que atingem qualquer classe, qualquer idade, em qualquer nível", argumenta a Dra. Anahy D'amico (apud GOMES, 2007, p. 38). "0 programa deseja, a princípio, que as pessoas entendam que todos os problemas são iguais para todo mundo, independente de sua faixa etária, da sua classe econômica", ratifica a produtora e assistente de direção Melissa Ribeiro (idem, p. 39).

0 enquadramento discursivo de Casos de Família dá a impressão de que a vida familiar é condicionada apenas e tão-somente por fatores internos (emoções e sentimentos, configurados como social e culturalmente desenraizados). Tanto a apresentadora quanto os "consultores em comportamento" tendem a menosprezar as possíveis influências do ritmo, das demandas e do estresse da vida cotidiana (a desgastante distância entre a residência e o local de trabalho; o desemprego que impossibilita ao homem assumir a condição, por ele almejada, de provedor da família) nas desavenças conjugais, na frieza ou na impaciência com os filhos e no alcoolismo, mesmo quando essas agruras sociais teimam em vir à baila durante os relatos dos participantes.

Na edição intitulada "Você passa muito tempo no banheiro" (08/09/08), em três das quatro famílias presentes ficava nítido que o cerne do problema era 0 fato de haver somente um banheiro em residências onde moravam diversas pessoas (treze, em um dos casos). Tal aspecto, contudo, não foi salientado em nenhuma ocasião por Regina Volpato. Enquanto Marlene, participante que morava em um quartinho nos fundos da casa do irmão, esclarecia que usava o banheiro de lá por não ter de dinheiro para construir um em seu próprio cômodo, Regina exibia certo ar de incredulidade, como se ignorasse que a construção de um toalete, com todas as instalações hidráulicas necessárias, ultrapassa o orçamento de muitas famílias. 0 Dr. Ildo Rosa também parecia míope para a raiz do problema: "Marlene, você não tem outra opção que não seja mandar fazer o outro banheiro, e parece que nem o projeto dele ainda existe [o expert ri, nesse momento ]". Não foi aventado de onde viriam os recursos para tal empreitada (nos tempos de Ratinho, provavelmente um político ou um empresário boa-praça se encarregaria da obra, em troca da publicidade espontânea). 
No talk show do SBT, o universalismo emocional eclipsa os constrangimentos de classe; 0 hiperinflacionado discurso do agenciamento e da responsabilidade individual encobre as circunstâncias sociais objetivas que impedem os convidados de realizarem suas aspirações. A concretização de projetos de melhoria de vida é relacionada, quase sempre, à livre disposição moral do indivíduo para engajar-se em sua reforma e seu crescimento pessoal. Em vez de lamentar a falta de dinheiro ou de reivindicar a igualdade de direitos, os participantes são exortados a sentirem-se responsáveis por superar "situações desfavoráveis" e "fatalidades da vida" - mudando a maneira de pensar e de agir, cultivando emoções positivas, atitudes receptivas e pensamentos otimistas. No programa do dia 16 de setembro de 2008, "Se você não me sustentar, eu vou embora de casa", Mariana declarou que, às vezes, os filhos pediam pão, biscoito, leite, e ela não tinha dinheiro para comprar, já que o marido estava desempregado. "E por que você não está conseguindo lidar com isso?", questionou Regina, com o cenho quase franzido. A fome foi abordada pela apresentadora como um problema de "manejo emocional" e não como uma questão objetiva (física e moralmente dolorosa) atrelada a interações, processos e decisões de caráter coletivo.

Fiel aos ensinamentos dos manuais de auto-ajuda e dos tratados pretensamente científicos da psicologia positiva, Casos de Família proclama
- com incansável determinação - que cada um deve identificar nos seus próprios recursos interiores (nas forças e nas virtudes individuais) os meios para conquistar a felicidade. "Nada nem ninguém possui o poder de estragar a vida de outra pessoa. A gente precisa ir atrás do que a gente quer", incentiva Regina Volpato. "Mais importante do que ganhar o peixe, é aprender o seu próprio jeito de pescar", inova a Dra. Anahy D'amico. Nenhuma palavra a respeito do custo do equipamento de pesca ou do fato de que águas do rio, amiúde, têm dono.

\section{Considerações finais}

Essa tal de sociedade não existe. Existem os indivíduos e as suas famílias.

Margaret Thatcher: The revival of Britain: speeches on home and economic affairs, 1975-1988 (1989)

Ao franquear ao cidadão comum e aos grupos minoritários o direito de expressão midiática, os novos programas de realidade funcionam, muitas vezes, como uma forma operacionalmente barata e discursivamente persuasiva de a indústria televisiva legitimar a sua "função social". Não se pode subestimar 0 apelo dessa retórica - mesmo no âmbito acadêmico. Basta examinar os diversos estudos que avaliam os talks shows populares como índice de uma efetiva democratização tanto no acesso ao espectro televisivo quanto na dinâmica do reconhecimento público (FREIRE FILHO, 2007b). 
Tal postura crítica já se afigura como demasiadamente "receptiva", mesmo quando restrita aos talk shows norte-americanos mais ruidosos e irreverentes. Identificar um potencial empoderador ${ }^{14}$ no autodesvelamento incitado pelo nosso contido Casos de Família requer, então, um grau desmedido de "pensamento otimista".

Conforme destacamos anteriormente, a vida familiar é tratada, no programa do SBT, sob a perspectiva de uma psicologia individualista, que menospreza o impacto do mundo social sobre o pessoal e o doméstico. A explicação para o comportamento dos entrevistados realça as peculiaridades, o "temperamento", os "complexos" e as "manias" de um self privado. Com seu foco unilateral no indivíduo, Casos de Família não fomenta a percepção crítica das persistentes e institucionalizadas desigualdades de classe e gênero. A conduta machista, por exemplo, tende a ser avaliada como uma forma de preconceito enraizada na estrutura profunda do "caráter" ou da "personalidade" de determinados maridos e companheiros, e não no "senso comum" geralmente aceito em sociedades patriarcais.

É altamente problemático, também, aplicar a Casos de Família o argumento (formulado, com regularidade, por pesquisadores dos estudos culturais ingleses e estadunidenses) de que os talk shows populares constituem arenas ideais para a expressão de desafios contra a autoridade televisiva e contra os conhecimentos peritos, em nome da experiência de primeira mão e das perspectivas e dos valores das pessoas comuns.

Em primeiro lugar, a atuação no programa é cuidadosamente pré-moldada e regida pela classificação prévia do drama particular a ser discutido e pela categorização dos convidados sob rótulos estereotipados (a esposa "possessiva", "gastadora", "relapsa" ou "superexigente"; o marido "infiel", "avaro", "beberrão" ou "superexigente"; a sogra "intrometida"; 0 filho "rebelde", "ingrato", "acomodado", e por aí vai). 0 processo de enquadramento dos participantes envolve, ainda, as normas de etiqueta promulgadas, preliminarmente, pela produção e pela anfitriã.

Além disso, a avaliação final da conduta dos participantes compete sempre ao "especialista em comportamento" (a derradeira intervenção de Regina Volpato se restringe, como vimos, a pronunciamentos de caráter universal a favor da solidariedade e do companheirismo ou ao enaltecimento da especial franqueza de uma convidada). Com postura menos branda e complacente do que a da anfitriã, a Dra. Anahy D'amico e o Dr. Ildo Rosa Fonseca (sempre 
apresentados com o nome completo pelo gerador de caracteres, diferentemente dos demais integrantes do programa) destinam os cinco minutos (em média) de sua performance televisiva à iluminação psicológica e à reeducação sentimental dos convidados. Os discursos dos peritos se caracterizam por uma combinação palatável de arrazoados bem-quistos pelo senso comum, ponderações sobre fenômenos mentais e emocionais, pronunciamentos sentenciosos, palavras reconfortantes e repreensões às vezes bastante severas.

Durante a apresentação do tema "Você tem que pensar antes de falar" (09/09/08), Dr. Ildo pontificou: "Eu percebi uma angústia, uma dor muito grande na sua fala o tempo todo, Alessandra, e as pessoas mudam sim, você não mudou ainda porque você tentou, e quem tenta qualquer coisa na vida não realiza, realizam as pessoas que fazem." Quando o assunto proposto pelo programa foi "Você não pára de falar" (04/09/08), a Dr. Anahy assegurou, inicialmente, que a loquacidade constitui um predicado normal do cérebro das mulheres; em seguida, recomendou que as convidadas procurassem uma terapia, a fim de entender por que são tão ansiosas e desejam tanto aparecer (ciente da impossibilidade de apreciar os casos mais complexos durante o perímetro de duração do programa, a psicóloga indica, vez ou outra, locais onde é possível marcar consultas terapêuticas gratuitas, como universidades). Mesmo quando colocados na berlinda, os convidados não têm direito à réplica - todos ouvem placidamente as lições dos experts.

Caso de Família colabora, inegavelmente, para que questões pessoais se tornem públicas; a visibilização do privado ocorre, porém, dentro de uma formatação que neutraliza os efeitos políticos progressistas ambicionados pela provocação feminista "0 pessoal é político". 0s problemas e as suas soluções são obsessivamente confinados pelo programa nos espaços interiores da casa, do coração, da alma e do consultório terapêutico - ou de sua extensão, simultaneamente acolhedora e espetacular, 0 estúdio de TV.

\section{Referências Bibliográficas}

BR00KS, Peter. The melodramatic imagination. Nova Iorque: Columbia University Press, 1984.

CHARAUDEAU, Patrick; GHIGLIONE, Rodolphe. A palavra confiscada - um gênero televisivo: 0 talk show. Lisboa: Instituto Piaget, 1997.

CORTÉS LAHERA, José Angel. Los talk shows. In: ___ La estratégia de la seducción - la programación en la neotelevisión. Pamplona: Universidad de Navarra, 1994, p. 199-205.

DUBROFSKY, Rachel E. Therapeutics of self: surveillance in the service of the therapeutic. Television \& New Media, vol. 8, n. 4, p. 263-284, 2007. FISKE, John. Television culture. Londres: Routledge, 1989. FREIRE FILHO, João. 0 debate sobre a qualidade da TV no Brasil: da trama dos discursos à tessitura das práticas. In: BORGES, Gabriela; REIA-BAPTISTA, Vítor (orgs.). Discursos e práticas de qualidade na televisão da Europa e América Latina. Lisboa: Ciccoma, 2008, p. 43-56. 
Como ser uma adolescente liberada no novo milênio. In: Reinvenções da resistência juvenil: os estudos culturais e as micropolíticas do cotidiano. Rio de Janeiro: Mauad, 2007a, p. 111-162.

A celebrização do ordinário na TV:

democracia radical ou neopopulismo midiático? In: ; HERSCHMANN, Micael (orgs.). Novos rumos da cultura da mídia: indústrias, produtos, audiências. Rio de Janeiro: Mauad X, 2007b, p. 59-82.

GLYNN, Kevin. Tabloid culture - Trash taste, popular power, and the transformation of American television. Londres: Duke University Press, 2000.

GOMES, Elisa da Silva. Casos de Família: a conjugalidade nas antenas da TV. 2007. Dissertação (Mestrado em Ciências Sociais) - Instituto de Filosofia e Ciências Humanas, Universidade do Estado do Rio de Janeiro, 2007.

IMBERT, Gerard. El talk show: o la verbalización del dolor. In: El zoo visual - de la televisión espectacular a la televisión especular. Barcelona: Gedisa, 2003, p. 123-142.

LANDY, Marcia (ed.). Imitations of life - a reader on film and television melodrama. Detroit: Wayne State University Press, 1991.

LIVINGSTONE, Sonia; LUNT, Peter. Talk on television: audience participation and public discourse. Londres: Routledge, 1994.

MARTÍN-BARBER0, Jesús. Dos meios às mediações - Comunicação, cultura e hegemonia. Rio de Janeiro: Ed. UFRJ, 2002.

MEHL, Dominique. La télévision de l'intimité. French Cultural Studies, vol. 18, n. 2, p.153-167, 2007.

. La bonne parole. Quand les psys plaident dans les médias. Paris : La Martinière, 2003.

La télévision relationnelle. Cahiers

Internationaux de sociologie, vol. 1, n. 112, p. 63-95, 2002.
. La télévision de l'intimité. Paris: Seuil, 1996.

MIRA, Maria Celeste. Circo eletrônico - Súlvio Santos e o SBT. São Paulo: Loyla/Olho D'Água, 1995.

PECK, Janice. TV talk shows as therapeutic discourse: the ideological labor of the televised talking cure. Communication Theory, vol. 5, n. 1, p.58-81, 1995.

SHATTUC, Jane. The shifting terrain of American talk shows. In: WASKO, Janet (ed.). A companion to television. Oxford: Blackwell, 2005, p. 324-336.

The talking cure: TV talk shows and women. Londres: Routledge, 1997.

SINGER, Ben. Melodrama and modernity. Early sensational cinema and its contexts. Nova Iorque: Columbia University Press, 2001

SODRÉ, Muniz. A comunicação do grotesco introdução à cultura de massa brasileira. Petrópolis, RJ: Vozes, 1992 [1972].

SODRÉ, Muniz \& PAIVA, Raquel. 0 império do grotesco. Rio de Janeiro: MAUAD, 2002.

WHITE, Mimi. Tele-advising: therapeutic discourse in American television. Chapel Hill: University of North Carolina Press, 1992.

Television, therapy, and the social subject: or, the TV therapy machine. In: FRIEDMAN, James (ed.). Reality squared: televisual discourse on the real. New Brunswick, NJ: Rutgers University Press, 2002, p. 313-322.

ZALDUENDO, Charo Lacalle. Mitologías cotidianas y pequeños rituales televisivos. Los talk shows. Anàlisi, n. 24 , p. $79-92,2000$. 


\section{"There's no such thing as society...": The private, the popular and the expert on the talk show Casos de Família}

\section{Abstract}

Based on a case study of the afternoon talk show Casos de Família (from SBT network), this article aims to provide new analytical perspectives on the pleasures, meanings, and socio-political implications of the present trend of exposing the private lives of ordinary people. How does Casos de Familia connect to, or distance itself from, the parameters of melodrama and grotesque realism usually embraced by popular TV shows in Brazil? What values are privileged by the talk show? How do they connect to the construction of forms of subjectivity that are crucial to the exercise of power in contemporary society? These are key inter-related issues that we intend to answer. This article is part of a wider research project on the renewed strategies of incorporation and interpellation of the popular on TV.

\section{Keywords}

Casos de Família. Talk show. Melodrama and grotesque realism. Private life. Power.

\section{"La sociedad no existe...": Lo privado, lo popular y lo perito en el talk show Casos de Família}

\section{Resumen}

Con base en el estudio de caso del talk show vespertino Casos de Família (SBT), este artículo pretende contribuir a la formulación de nuevos parámetros para la investigación de los placeres, de los significados culturales y de las implicaciones sociopolíticas de la actual tendencia de exposición de la vida privada de la "gente común". ¿De que manera Casos de Família se acerca o se aleja de las matrices del melodrama y del realismo grotesco, que tradicionalmente son accionados por programas populares en Brasil? ¿Qué valores son favorecidos por el talk show? ¿Cómo ellos se conectan con la construcción de formas de subjetividad fundamentales al ejercicio del poder en la actualidad? Son estas las cuestiones esenciales interrelacionadas que pretendemos responder en el ámbito de una investigación más amplia sobre las renovadas estrategias de incorporación e interpelación lo popular en la televisión.

\section{Palabras clave}

Casos de Família. Talk show. Matrices populares. Vida privada. Poder. 


\section{Expediente}

A revista E-Compós é a publicação científica em formato eletrônico da Associação Nacional dos Programas de Pós-Graduação em Comunicação (Compós). Lançada em 2004, tem como principal finalidade difundir a produção acadêmica de pesquisadores da área de Comunicação, inseridos em instituições do Brasil e do exterior.
E-COMPÓS I www.e-compos.org.br I E-ISSN 1808-2599

Revista da Associação Nacional dos Programas de Pós-Graduação em Comunicação. Brasília, v.11, n.2, maio/ago. 2008.

A identificação das edições, a partir de 2008 passa a ser volume anual com três números.

\section{CONSELHO EDITORIAL}

\section{Afonso Albuquerque}

Universidade Federal Fluminense, Brasil

Alberto Carlos Augusto Klein

Universidade Estadual de Londrina, Brasi

Alex Fernando Teixeira Primo

Universidade Federal do Rio Grande do Sul, Brasi

Alfredo Vizeu

Universidade Federal de Pernambuco, Brasil

Ana Carolina Damboriarena Escosteguy

Pontifícia Universidade Católica do Rio Grande do Sul, Brasil

Ana Silvia Lopes Davi Médola

Universidade Estadual Paulista, Brasil

André Luiz Martins Lemos

Universidade Federal da Bahia, Brasil

Ângela Freire Prysthon

Universidade Federal de Pernambuco, Brasi

Antônio Fausto Neto

Universidade do Vale do Rio dos Sinos, Brasil

Antonio Carlos Hohlfeldt

Pontifícia Universidade Católica do Rio Grande do Sul, Brasil

Arlindo Ribeiro Machado

Universidade de São Paulo, Brasil

César Geraldo Guimarães

Universidade Federal de Minas Gerais, Brasi

Cristiane Freitas Gutfreind

Pontifícia Universidade Católica do Rio Grande do Sul, Brasi

Denilson Lopes

Universidade Federal do Rio de Janeiro, Brasil

Eduardo Peñuela Cañizal

Universidade Paulista, Brasil

Erick Felinto de Oliveira

Universidade do Estado do Rio de Janeiro, Brasil

Francisco Menezes Martins

Universidade Tuiuti do Paraná, Brasil

Gelson Santana

Universidade Anhembi/Morumbi, Brasi

Hector Ospina

Universidad de Manizales, Colômbia

leda Tucherman

Universidade Federal do Rio de Janeiro, Brasil

Itania Maria Mota Gomes

Universidade Federal da Bahia, Brasil

Janice Caiafa

Universidade Federal do Rio de Janeiro, Brasil

Jeder Silveira Janotti Junior

Universidade Federal da Bahia, Brasil
John DH Downing

University of Texas at Austin, Estados Unidos

José Luiz Aidar Prado

Pontifícia Universidade Católica de São Paulo, Brasil

José Luiz Warren Jardim Gomes Braga

Universidade do Vale do Rio dos Sinos, Brasi

Juremir Machado da Silva

Pontifícia Universidade Católica do Rio Grande do Sul, Brasil

Lorraine Leu

University of Bristol, Grã-Bretanha

Luiz Claudio Martino

Universidade de Brasília, Brasil

Maria Immacolata Vassallo de Lopes

Universidade de São Paulo, Brasil

Maria Lucia Santaella

Pontifícia Universidade Católica de São Paulo, Brasil

Mauro Pereira Porto

Tulane University, Estados Unidos

Muniz Sodre de Araujo Cabral

Universidade Federal do Rio de Janeiro, Brasil

Nilda Aparecida Jacks

Universidade Federal do Rio Grande do Sul, Brasil

Paulo Roberto Gibaldi Vaz

Universidade Federal do Rio de Janeiro, Brasil

Renato Cordeiro Gomes

Pontifícia Universidade Católica do Rio de Janeiro, Brasil

Ronaldo George Helal

Universidade do Estado do Rio de Janeiro, Brasil

Rosana de Lima Soares

Universidade de São Paulo, Brasil

Rossana Reguillo

Instituto Tecnológico y de Estudios Superiores do Occidente, México

Rousiley Celi Moreira Maia

Universidade Federal de Minas Gerais, Brasil

Sebastião Carlos de Morais Squirra

Universidade Metodista de São Paulo, Brasil

Simone Maria Andrade Pereira de Sá

Universidade Federal Fluminense, Brasil

Suzete Venturelli

Universidade de Brasília, Brasil

Valério Cruz Brittos

Universidade do Vale do Rio dos Sinos, Brasil

Veneza Mayora Ronsini

Universidade Federal de Santa Maria, Brasil

Vera Regina Veiga França

Universidade Federal de Minas Gerais, Brasil
COMISSÃO EDITORIAL

Ana Gruszynski I Universidade Federal do Rio Grande do Sul, Brasil João Freire Filho I Universidade Federal do Rio de Janeiro, Brasil Rose Melo Rocha I Escola Superior de Propaganda e Marketing, Brasil

\section{CONSULTORES AD HOC}

Aníbal Bragança I Universidade Federal Fluminense, Brasil Gisela Castro I Escola Superior de Propaganda e Marketing, Brasil

Gislene Silva I Universidade Federal de Santa Catarina, Brasil

Maria Helena Weber I Universidade Federal do Rio Grande do Sul, Brasil

Rosana de Lima Soares I Universidade de São Paulo, Brasil

Tania Hoff I Escola Superior de Propaganda e Marketing, Brasil

REVISÃO DE TEXTO E TRADUÇÃo I Everton Cardoso

ASSISTÊNCIA EDITORIAL E EDITORAÇÃO ELETRÔNICA I Raquel Castedo
COMPÓS I www.compos.org.br

Associação Nacional dos Programas de Pós-Graduação em Comunicação

Presidente

Erick Felinto de Oliveira

Universidade do Estado do Rio de Janeiro, Brasil erickfelinto@uol.com.br

Vice-presidente

Ana Silvia Lopes Davi Médola

Universidade Estadual Paulista, Brasil

asilvia@faac.unesp.br

Secretária-Geral

Denize Correa Araújo

Universidade Tuiuti do Paraná, Brasil

denizearaujo@hotmail.com 